\title{
Fuzzy Logic based PID Controller for pH Neutralization Process
}

\author{
Irene Martina Jebarani.D \\ Department of ECE , \\ Adithya Institute of Technology, Kurumbapalayam, \\ Coimbatore-641107, Tamilnadu, India
}

\author{
T.Rammohan \\ Associate Professor, Department of ECE, \\ Adithya Institute of Technology,Kurumbapalayam, \\ Coimbatore-641107, Tamilnadu, India
}

\begin{abstract}
The automation of a Water treatment plant involves monitoring and control of various parameters like Temperature, Pressure, Level, Flow and Vibration in the plant. Process Control plays a major role in the automation industry. The intricacy of any control mechanism has only increased due to an unprecedented increase in the requirements, instrumentation and various control loops. Therefore a simple PID control mechanism is not a practical option for efficient control of any real - time process, let alone automation of an entire plant. This paper presents an improved version of the classic PID control mechanism that is the use of Fuzzy control logic along with the PID control for the $\mathrm{pH}$ neutralization process in a water treatment plant. The implementation of this procedure will be relevant for any multivariable process.
\end{abstract}

\section{General Terms}

Automation, Industrial multivariable process

\section{Keywords}

Water treatment plant, classic PID, Fuzzy logic control, pH neutralization process, multivariable process

\section{INTRODUCTION}

There are many controller mechanisms used in a water treatment plant, narrowing down to an effective mechanism from among the many is a tough task for any process including the $\mathrm{pH}$ neutralization process. The selection of the control mechanism is fraught with difficulties because of the Control system design for $\mathrm{pH}$ neutralization is technically difficult to implement [27], owing to its non-linear responses, sensitive environment uncertain results and large number of requirements. Classical control mechanisms hold good only for linear, theory based processes. These simple mechanisms do not work as well when applied to constantly changing chemical systems with complex kinetic and thermodynamic reactions. These classical control mechanisms fail miserably when it comes to system performances and does not cover the whole range of operation.

The range of $\mathrm{pH}$ values between 1 and 14 is a scale to measure acidity of any system. If the $\mathrm{pH}$ value of a solution is less than 7 at room temperature, the concentration of hydrogen ions in the solution is high, thus the solution is an acid. If the $\mathrm{pH}$ value of a solution is greater than 7 at room temperature, the concentration of hydroxyl ions in the solution is high, thus the solution is alkaline or a base. On the other hand, if the $\mathrm{pH}$ value of any solution is 7 , then the solution is considered to be neutral. According to environmental safety standards for industries all treated water effluents must have a $\mathrm{pH}$ value of either $7+1$ or $7-1$.

PID logic control mechanism is based on optimal tuning of the control parameters such as proportional gain, integral gain and derivate gain according to the changes in the process [18]. Fuzzy logic control is based on the choice of an appropriate membership function for the input and output set of parameters.

Standalone classical PID control or Fuzzy logic based control does not provide an ideal performance. Rather a combination of the classical PID logic along with Fuzzy logic based control [29] provides an optimally performing intelligent system.
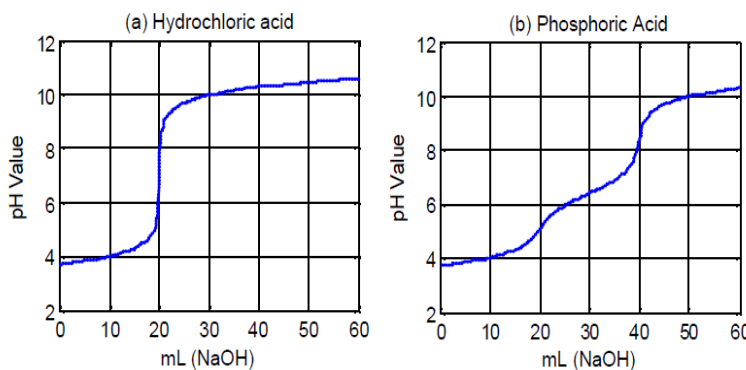

Figure 1: Titration curve for acid-base process reaction

PID logic control mechanism is based on optimal tuning of the control parameters such as proportional gain, integral gain and derivate gain according to the changes in the process[8]. Fuzzy logic control is based on the choice of an appropriate membership function for the input and output set of parameters. Standalone classical PID control or Fuzzy logic based control does not provide an ideal performance. Rather a combination of the classical PID logic along with Fuzzy logic based control [6] provides anoptimally performing intelligent system.

\section{LITERATURE REVIEW}

A commonly applicable method for derivation of dynamic equations for $\mathrm{pH}$ neutralization in aContinuous Stirred Tank Reactor is presented in [8, 24]. In [1], the same control for neutralization process control. A theory to average the value of a mixture of solutions is introduced in [11, 14], utilizing reaction invariant variables to calculate value of mixtures of 
solutions, instead of simple averaging of hydrogen ions. The combination of ions is presented in [7]. In [15], a systematic method for the modeling of dynamics of the neutralization process is introduced. A theoretical species estimation to obtain the inverse titration curve is developed so that the linearization of the control loop can be utilized. Fundamental properties of continuous control are investigated in [19] using PIDcontroller. Nonlinear adaptive control for $\mathrm{pH}$ neutralization process using a CSTR is presented in [2]. Method of determination of $\mathrm{pH}$ value and control is used from $[3,12]$.

In $[16,5]$ the performance of the system on a neutralization system is evaluated in order to gain additional understanding in terms of real-world applications. A nonlinear controller using feedback is developed in [34] by linearizing input given to a non - varying model of the process by using a PI controller which uses nonlinear results and a recursive least squares parameter estimator. A mathematical modeling of the neutralization process in a CSTR based on a physio-chemical approach is presented in [14]. In [11], an adaptive control for a chemical waste water treatment plant is also presented. The same method is used in [15]. In [20 and 25], author presented a new approach for an adaptive combined feedback-feed forward control method for control which was based on a quantitative physio-chemical analysis of the neutralization process. However, this work has high SNR. A similarmethod is extended by using an adaptive controller in [13]. Anassessment of linear and non-linear control for $\mathrm{pH}$ neutralization is presented in [6]. In [5, 33], the study of the controller's performance, such as tracing flow-rate set point, operation ,study of settings of normal process operation and. A new methodof control using a reactor to include the nonlinearities of the neutralization process is described in [31]. Indirect adaptive nonlinear control of $\mathrm{pH}$ neutralization process is presented in [34]. In [20 and 26] practical control design issues for neutralization are investigated with the objective to design an adaptive identification method using extended Kalman filter. In [4, 13, and 17] author outlines the basis of the controller and develops a fuzzy relationship model which is based on fuzzy inference.Relatedmethods are discussed in [6, 9, 22, and 23]. In [33, 31 and 30], a method using genetic algorithm is used to modify membership functions in reaction to changes in the process. In [10, 26 and 28] a fuzzy based PID control of non-linear system is applied but this work doesn't consider the system's features involving delays in signal transmission. Mathematical modeling of $\mathrm{pH}$ process is done as in [21 and 32].

\section{PROPORTIONAL INTEGRAL DERIVATIVE (PID) CONTROL DESIGN}

Fig 2 shows the characteristics curves for flow rates of the acid and alkaline valves in a $\mathrm{pH}$ neutralization mechanism. The flow rates are measured using flow meters. It can be seen that flow controlfor the opening of the valves (up scaling) and the closing of the valves (down scaling) is different. The PID control logic is designed to set right the error value that varies from $2 \%$ to $6 \%$ [1]. Initially, the proportional gain is a minimum value and the integral and derivative terms are set to give no(zero) action. The proportional gain is slowly increased until oscillations start appearing in the response of the closed-loop system. The gain is later adjusted to maintain the oscillations at single constant value of amplitude [3]. The value of gain that achieves this condition of constant amplitude oscillations is thefinal proportional gain with value $(\mathrm{G}=18)$ at the period 33 .
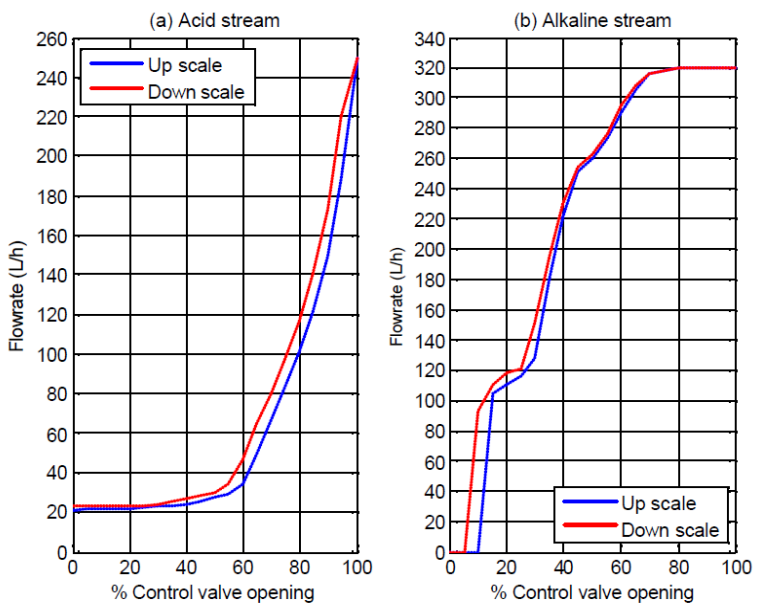

Figure 2: Flow-rates of acid and alkaline streams

Based on Table 2 proportional gain is $\mathrm{Kp}=10.8$, integral gain is $\mathrm{Ki}=0.65$ and derivative gain is $\mathrm{Kd}=44.5$.

Table 2: Ziegler-Nichols tuning formula for a closed loop

\begin{tabular}{|l|l|l|l|}
\hline Type of controller & P & PI & PID \\
\hline Proportional Kp & $0.5 \mathrm{G}$ & $0.45 \mathrm{G}$ & $0.6 \mathrm{G}$ \\
\hline Integral Ki & - & $1.2 \mathrm{Kp} / \mathrm{P}$ & $2 \mathrm{Kp} / \mathrm{P}$ \\
\hline Differential Kd & - & - & $\mathrm{KpP} / 8$ \\
\hline
\end{tabular}

\section{FUZZY LOGIC CONTROLLER DESIGN}

Fuzzy logic controller mainly consists of three sections or steps:

(i) Fuzzification: It is the process of converting the process variables (system inputs) into grades of membership

(ii) Fuzzy interference: It is the process of mappingthe input space on to output space using membership functions, logic operations and if-then rule statements

(iii) Defuzzification: It is the process of providing quantifiable values (control valve inputs for PID controller) in terms of given fuzzy sets and membership degree.

The performance of fuzzy control logic is dependent on the choice of the membership function of input and output sets.All the process variables are controlled automatically, with the set point being the only exception, which is set manually [9].The automatic control of the other variables is done on the basis of the feedback from the output values. The fuzzy controller maintains the corresponding value while controlling the process control variables [2]. When the current value is less than the desired value, Fuzzy logic controller sets a newvalue for the set point PID flow rate controller. The new value of current set point is decided by the difference between the current value of the plant reactor and the desired value. The overall diagram is shown in Fig. 3 


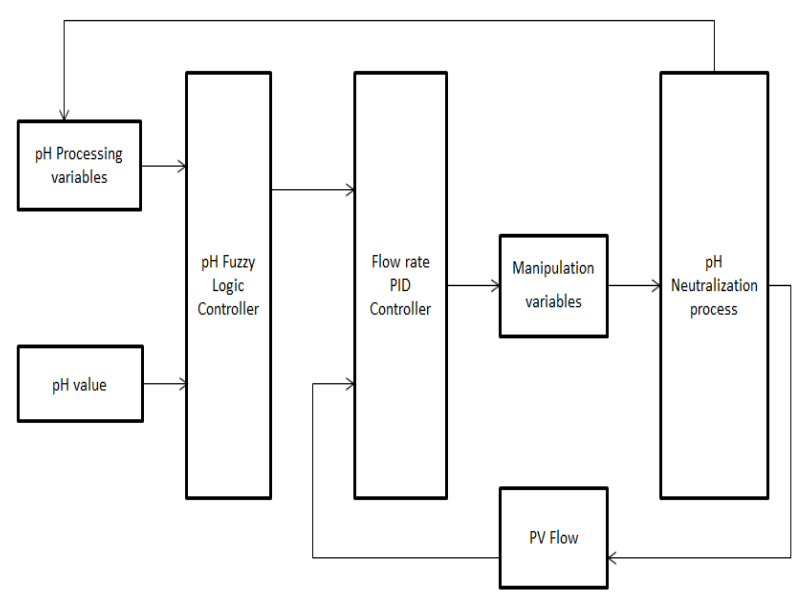

Figure 3: Logical diagram of fuzzy based PID controller

Figure 4 shows the input membership for input set 1 , which is the measured $\mathrm{pH}$ value. The central condition is between -0.5 and 0.5 to guarantee the evenness of the desired value and to make the achievement of zero offset for steady state possible. The overall performance of the system is given by the input and output sets membership functions.

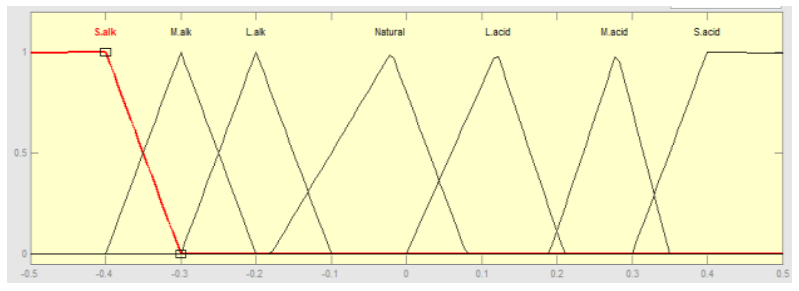

Figure 4:Membership function of input set 1.

Figure 5 shows the membership function of input set 2, which is the set point of $\mathrm{pH}$ and isentered manually.

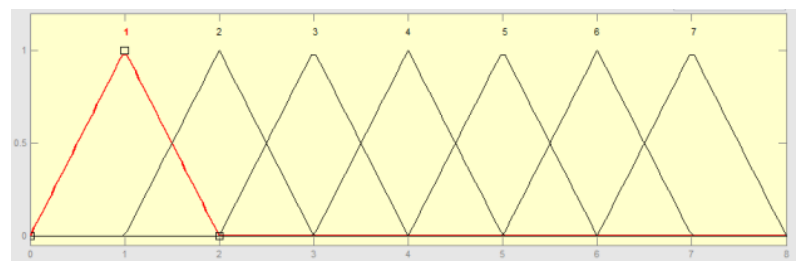

Figure 5: Membership function of input set 2.

Figure 6 shows themembership functionof output set.The output set is the set of output values to control the opening of acid and alkaline control valves.

Table 4, shows the rule base for firing the inputs and to give rise to the right output values so as to control the $\mathrm{pH}$ value at the right level.

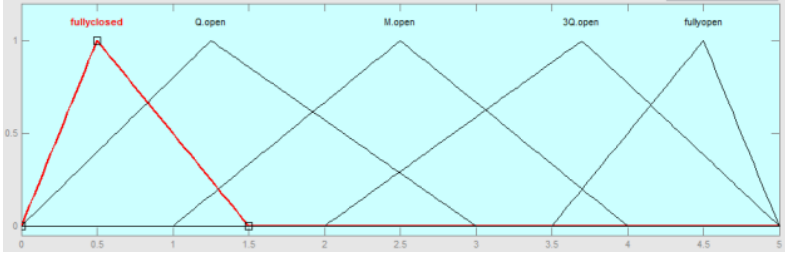

Figure 6: Membership function of output set.

Table 4: Rule base

\begin{tabular}{|c|c|c|c|c|c|c|c|}
\hline & PH 1 & PH 2 & PH 3 & $\overline{\mathrm{PH}} 4$ & PH 5 & PH 6 & PH 7 \\
\hline Sacid & $\begin{array}{l}\text { FULLY } \\
\text { CLOSE }\end{array}$ & $\begin{array}{c}\mathbf{Q} \\
\text { OPEN }\end{array}$ & $\begin{array}{c}\mathrm{M} \\
\text { OPEN }\end{array}$ & $\begin{array}{c}\mathrm{M} \\
\text { OPEN }\end{array}$ & $\begin{array}{c}\mathrm{M} \\
\text { OPEN }\end{array}$ & $\begin{array}{c}Q \\
\text { OPEN }\end{array}$ & $\begin{array}{c}Q \\
\text { OPEN }\end{array}$ \\
\hline Macid & $\begin{array}{l}\text { FULLY } \\
\text { OPEN }\end{array}$ & $\begin{array}{c}3 Q \\
\text { OPEN }\end{array}$ & $\begin{array}{c}M \\
\text { OPEN }\end{array}$ & $\begin{array}{c}\mathrm{Q} \\
\text { OPEN }\end{array}$ & $\begin{array}{l}\text { FULLY } \\
\text { CLOSE }\end{array}$ & $\begin{array}{l}\text { FULLY } \\
\text { CLOSE }\end{array}$ & $\begin{array}{l}\text { FULLY } \\
\text { CLOSE }\end{array}$ \\
\hline b.acid & $\begin{array}{l}\text { FULLY } \\
\text { OPEN }\end{array}$ & $\begin{array}{l}\text { FULLY } \\
\text { OPEN }\end{array}$ & $\begin{array}{c}3 Q \\
\text { OPEN }\end{array}$ & $\begin{array}{c}\text { M } \\
\text { OPEN }\end{array}$ & $\begin{array}{c}\mathbf{M} \\
\text { OPEN }\end{array}$ & $\begin{array}{l}\text { FULLY } \\
\text { CLOSE }\end{array}$ & $\begin{array}{l}\text { FULLY } \\
\text { CLOSE }\end{array}$ \\
\hline Natural & $\begin{array}{c}\text { M } \\
\text { OPEN }\end{array}$ & $\begin{array}{c}\text { M } \\
\text { OPEN }\end{array}$ & $\begin{array}{c}\mathbf{Q} \\
\text { OPEN }\end{array}$ & $\begin{array}{c}\mathbf{Q} \\
\text { OPEN }\end{array}$ & $\begin{array}{c}\mathbf{Q} \\
\text { OPEN }\end{array}$ & $\begin{array}{c}\mathbf{Q} \\
\text { OPEN }\end{array}$ & $\begin{array}{l}\text { FULLY } \\
\text { CLOSE }\end{array}$ \\
\hline L.alk. & $\begin{array}{c}\text { 3Q } \\
\text { OPEN }\end{array}$ & $\begin{array}{c}\text { BQ } \\
\text { OPEN }\end{array}$ & $\begin{array}{c}Q \\
\text { OPEN }\end{array}$ & $\begin{array}{c}\text { BQ } \\
\text { OPEN }\end{array}$ & $\begin{array}{c}\mathbf{M} \\
\text { OPEN }\end{array}$ & $\begin{array}{c}\text { M } \\
\text { OPEN }\end{array}$ & $\begin{array}{c}\text { M } \\
\text { OPEN }\end{array}$ \\
\hline M.alk. & $\begin{array}{c}\text { 3Q } \\
\text { OPEN }\end{array}$ & $\begin{array}{c}\text { BQ } \\
\text { OPEN }\end{array}$ & $\begin{array}{c}\text { BQ } \\
\text { OPEN }\end{array}$ & $\begin{array}{c}\mathbf{M} \\
\text { OPEN }\end{array}$ & $\begin{array}{c}\text { M } \\
\text { OPEN }\end{array}$ & $\begin{array}{c}\mathbf{Q} \\
\text { OPEN }\end{array}$ & $\begin{array}{c} \\
\text { OPEN }\end{array}$ \\
\hline S. alk. & $\begin{array}{l}\text { FULLY } \\
\text { OPEN }\end{array}$ & $\begin{array}{l}\text { FULLY } \\
\text { OPEN }\end{array}$ & $\begin{array}{l}\text { FULLY } \\
\text { OPEN }\end{array}$ & $\begin{array}{l}\text { FULLY } \\
\text { OPEN }\end{array}$ & $\begin{array}{c}3 Q \\
\text { OPEN }\end{array}$ & $\begin{array}{c}3 Q \\
\text { OPEN }\end{array}$ & $\begin{array}{c}3 Q \\
\text { OPEN }\end{array}$ \\
\hline
\end{tabular}

\section{EXPERIMENTS}

The experiment is done to check the performance of the combination controller comprising of PID controller and fuzzy logic controller.
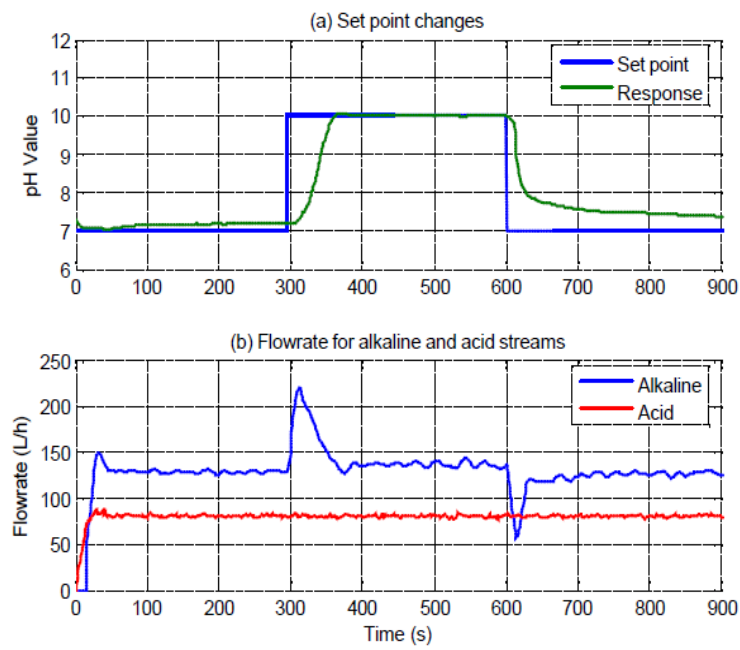

Figure 7: Performance of combination control mechanism.

The manual set point used is $\mathrm{pH}=7$. Here the typical amount of $\mathrm{H}_{2} \mathrm{SO}_{4}$ is mixed with typical amount of $\mathrm{NaOH}$ and two changes are made one is $\mathrm{pH}$ value $=7$ and the second is $\mathrm{pH}$ value $=10$. It helps in determining the response time of the system.

Another experiment is carried out to check the sturdiness of the combination controller. Here many set points are 
introduced in the form of a square wave at different time points. The range of input values are from $\mathrm{pH}=6$ to $\mathrm{pH}=$ 10 .The initial $\mathrm{pH}$ value remains unchanged and is set to 7 . The third experiment compares the performance of the combination controller of Fuzzy Logic and PID controller against normal Fuzzy Logic controller. For this experiment, $\mathrm{pH}$ value is varied from six to ten and the performance is observed.

\section{RESULTS}

The result of the experiment is shown in Fig. 7. It can be seen that initially the $\mathrm{pH}$ value is set to 7 and at a time interval of step $300 \mathrm{sec}$, the input to the system changes to $\mathrm{pH}=10$. Output trails the input and at time step $380 \mathrm{sec}$, output reaches $\mathrm{pH}=10$. But a delay can be seen in the output as the flow rate of the classical PID controller is dependent on the flow valves of acid and alkaline streams. The output follows the input as seen. The control valves have different rise and fall time and so the time delays are also different.

\section{CONCLUSION AND PROPOSED FUTURE WORK}

This paper presents a combination control mechanism (PID and fuzzy logic controller) for control $\mathrm{pH}$ neutralization process pilot plant. It covers the existing operating range of all $\mathrm{pH}$ values. It is also observed that the combination controller is high on stability when compared to the normal fuzzy logic controller. Practical tests are proposed to be carried out on a real time system to validate the proposed system in a practical environment.

The design methodology presented in this paper is applicable to any general $\mathrm{pH}$ neutralization process plant with mechanical flow meters. The sturdiness of the combination controller is dependent on the flow rate control valve, $\mathrm{pH}$ value meter, flow transmitter and concentration monitoring sensors as these instruments are the manipulating variables during real time controller design and implementation. Proposed future work is to design an adaptive neural network based controller can be used to achieve the same objective.

\section{REFERENCES}

[1] Alvarez, H., Londono, C., de Sciascio, F., \& Carelli, R., "PH neutralization process as a benchmark for testing nonlinear controllers", Industrial \& Engineering Chemistry Research, vol. 40, no. 11, pp. 2467-2473, 2001.

[2] Bar-Eli, K. \& Noyes, R. M., "A model for imperfect mixing in a CSTR", The Journal of Chemical Physics, vol. 85, no. 6, pp. 3251-3257, 1986.

[3] Bates, R. G., Determination of pH: Theory and Practice, 2 edn, John Wiley \& Sons, Inc, New York, 1973.

[4] B. Hamed and A. El Khateb, "Hybrid Takagi-Sugeno fuzzy FED PID control of nonlinear systems," Intelligent Systems and Automation, vol. 1019, pp. 99-102, 2008.

[5] Bohn, C. \& Atherton, D. P., "SIMULINK package for comparative studies of PID anti- windup strategies", Proceedings of the IEEE/IFAC Joint Symposium on Computer-Aided pp. 447-452, 1994.

[6] Bohn, C. \& Atherton, D. P., "Analysis package comparing PID anti-windup strategies", IEEE Control Systems Magazine, vol. 15, no. 2, pp. 34-40, 1995.
[7] Butler, J. N., Ionic Equilibrium : A Mathematical Approach Addison-Wesley Publishing, Inc., London.1964.

[8] Christian, G. D. , "Acid-Base Equilibria," in Analytical Chemistry, Sixth edn, John Wiley \& Sons, Inc., United States of America, pp. 214-260. 2004.

[9] George, J. K. \& Yuan B, Fuzzy Sets and Fuzzy Logic : Theory and Applications Prentice Hall, PTR, New Jersey.1995.

[10] Gong, M. \& Murray-Smith, D. J., "A practical exercise in simulation model validation", Mathematical and Computer Modelling of Dynamical Systems, vol. 4, no. 1, pp. 100-117.1998.

[11] Gustafsson, T. K., "Calculation of the $\mathrm{pH}$ value of a mixture solutions - an illustration of the use of chemical reaction invariants", Chemical Engineering Science, vol. 37, no. 9, pp. 1419-1421, 1982.

[12] Gustafsson, T. K. \& Waller, K. V., "Dynamic modeling and reaction invariant control of $\mathrm{pH}$ ", Chemical Engineering Science, vol. 38, no. 3, pp. 389-398., 1983.

[13] Gustafsson, T. K. \& Waller, K. V., "Nonlinear and adaptive control of $\mathrm{pH}$ ", Industrial \& Engineering Chemistry Research, vol. 31, no. 12, pp. 2681-2693, 1992.

[14] Gustafsson, T. K., Skrifvars, B. O., Sandstroem, K. V., \& Waller, K. V. "Modeling of pH for Control", Industrial \& Engineering Chemistry Research, vol. 34, no. 3, pp. 820$827,1995$.

[15] Harvey, D., Morden Analytical Chemistry The McGrawHill Companies, Inc., Singapore.2000.

[16] Henson, M. A. \& Seborg, D. E., "Adaptive nonlinear control of a pH neutralization process", Control Systems Technology, IEEE Transactions on, vol. 2, no. 3, pp. 169-182, 1994.

[17] Jamshidi, M., Ross, T. J., \& Vadiee, N., Fuzzy Logic and Control: Software and Hardware Applications Prentice Hall, Inc., New Jersey.1993.

[18] Jutila, P. \& Orava, J. P., "Control and Estimation Algorithms for Physico- Chemical Models of $\mathrm{pH}-$ Processes in Stirred Tank Reactors", International Journal of Systems Science,vol.12, no.7, pp.855-875, 1981.

[19] Jutila, P., "An application of adaptive pH-control algorithms based on physicochemical in a chemical waste-water treatment plant", International Journal of Control, vol. 38, no. 3, pp. 639-655.1983.

[20] Jutila, P. \& Visala, A., "Pilot plant testing of an adaptive $\mathrm{pH}$-control algorithm based on physico-chemical modelling", Mathematics and Computers in Simulation, vol. 26, no. 6, pp. 523-533, 1984.

[21] Karr, C. L., "Design of a cart-pole balancing fuzzy logic controller using a genetic algorithm", Proceeding of The International Society for Optical Engineering, vol. 1468, pp. 26-36.1991.

[22] Karr, C. L. \& Gentry, E. J, "Fuzzy control of pH using genetic algorithms", IEEE Transactions on Fuzzy Systems, vol. 1, no. 1, pp. 46-53.1993. 
[23] Kelkar, B. \& Postlethwaite, B. 1994, "Fuzzy- model based $\mathrm{pH}$ control", IEEE International Conference on Fuzzy Systems, vol. 1, pp. 661-666.1994.

[24] McAvoy, T. J., Hsu, E., \& Lowenthals, S., "Dynamics of $\mathrm{pH}$ in controlled stirred tank reactor", Ind Eng Chem Process Des Develop, vol. 11, no. 1, pp. 68-78, 1972.

[25] Murray-Smith, D. J, "Issues of Model Accuracy and External Validation for Control System Design", Acta Polytechnica, vol. 40, no. 3.2000.

[26] Murray-Smith, D. J., "Simulation Model Quality Issues In Engineering: A Review", Proceedings 5th Symposium on Mathematical Modelling, MATHMOD Vienna, Austria, 2006

[27] Norhaliza Abdul Wahab, Reza Katebi and Jonas Balderud "Multivariable PID control of an Activated Sludge Wastewater Treatment Process",Department of Control and Instrumentation Engineering, Faculty of Electrical Engineering, Universiti Teknologi Malaysia, Johor, Malaysia Industrial Control Centre, Dept of Electronic and Electrical Engineering,

[28] R. Ibrahim, "Practical modeling and control implementation studies on a ph neutalization plot plant", Department of Electronics and Electrical Engineering, University of Glasgow, 2008.
[29] S. Marsili-Libelli , G.M. Maietti, "Energy-saving through remote control of a wastewater treatment plant", Department of Systems and Computers, University of Florence, Via S. Marta 3,50139, Florence, Italy (E-mail: marsili@dsi.unifi.it)

[30] S. Vaishnav, Z. Khan. Design and Performance of PID and Fuzzy Logic Controller with Smaller Rule Set for Higher Order System. International Conference on Modeling, Simulation and Control, San Francisco, USA Pages 24-26: 855-858, 2007.

[31] Sung, S. W., Lee, I. B., \& Yang, D. R., "pH control using an identification reactor", Industrial and Engineering Chemistry Research, vol. 34, no. 7, pp. 2418- 2426, 1995.

[32] Wright, R. A., Smith, B. E., \& Kravaris, C., "On-Line identification and nonlinear control of $\mathrm{pH}$ processes", Industrial and Engineering Chemistry Research, vol. 37, no. 6 , pp. 2446-2461, 1998.

[33] Wright, R. A. \& Kravaris, C., "On- line identification and nonlinear control of an industrial $\mathrm{pH}$ process", Journal of Process Control, vol. 11, no. 4, pp. 361-374, 2001.

[34] Yoon, S. S., Yoon, T. W., Yang, D. R., \& Kang, T. S., "Indirect adaptive nonlinear control of a $\mathrm{pH}$ process", Computers and Chemical Engineering, vol. 26, no. 9, pp. 1223-1230, 2002 